\title{
Pensar las ciudadanías multiculturales: una apuesta para revisitar la ciudadanía intercultural en las sociedades actuales
}

Maguemati Wabgou ${ }^{1}$

\begin{abstract}
Resumen
Partiendo de la idea según la cual el multiculturalismo plantea problemas a la tradición de la ciudadanía y recurriendo a la noción de ciudadanía multicultural, el artículo busca cuestionar la ciudadanía en sus formas más tradicionales por medio de replanteamientos conceptuales y teóricos, identificando algunos escenarios de expresión de las ciudadanías multiculturales, con el fin de retomar la idea de las ciudadanías interculturales y aprehender las dinámicas de concreción y operatividad de la misma en las actuales sociedades modernas. Entonces, se evidencia que la noción tradicional de ciudadanía carece de recursos suficientes para gestionar los nuevos fenómenos sociales relacionados con la multiculturalidad y el multiculturalismo cuyas expresiones tienen que ver con nuevas identidades, culturas, cosmovisiones, conocimientos y saberes, etc., dentro del marco de los nuevos dinamismos de las instituciones básicas de la modernidad como el Estado y el mercado, igual que las complejas mutaciones modernas, postcoloniales y postmodernas. Se replantea así la ciudadanía intercultural como una categoría de análisis de nuestras sociedades contemporáneas, cuyas complejidades se reflejan cada vez más por medio de las interconexiones entre lo local y lo global.
\end{abstract}

Palabras clave: ciudadanías multiculturales, ciudadanía intercultural, interculturalidad, pluralismo cultural, sociedades actuales. 


\title{
Think about multicultural citizenship: a commitment to revisit intercultural citizenship in contemporary societies.
}

\begin{abstract}
Starting from the idea according to which multiculturalism discloses the problems of the tradition of citizenship and resorting to the notion of multicultural citizenship, the paper seeks to interrogate citizenship in its more traditional forms by means of conceptual and theoretical reframes, identifying some scenarios of expression of multicultural citizenship; in order to return to the idea of the intercultural citizenship and grasp the dynamics of its realization and operation in our current modern societies. Then, the article evidences the fact that the traditional notion of citizenship does not have sufficient resources to manage the new social phenomena related to the multiculturalism's expressions that have to do with new identities, cultures, traditional views, knowledge, etc., within the framework of the new dynamics of the basic institutions of modernity, such as the State and the market, as well as some complex, modern, postcolonial and postmodern mutations. Thus, the dissertation rethinks intercultural citizenship as a category of analysis of our contemporary societies whose complexities are reflected increasingly through the interconnections between the local and the global.
\end{abstract}

Keywords: Multicultural citizenship, intercultural citizenship, interculturality, cultural pluralism, current societies.

Recibido: 04-03-2014

Aceptado: 12-06-2014

\section{Introducción}

El artículo busca abrir un espacio de reflexión crítica en torno a la noción y construcción de las ciudadanías multiculturales en contextos globales, incluyendo los escenarios estatales, regionales y, sobre todo, locales donde hace presencia el «otro» como desplazado, inmigrante en situación de legalidad, ilegalidad y clandestinidad, inmigrante o desplazado negro, chino, latino, hombre/mujer, niño/niña, empresario, pobre, etc. Por lo tanto, invita a repensar la ciudadanía en sus formas más tradicionales por medio de cuestionamientos y replanteamientos conceptuales y teóricos con el fin de identificar algunos escenarios de expresión de dichas ciudadanías multiculturales y aprehender las dinámicas de concreción 
y operatividad de la misma en las sociedades actuales. En este orden de ideas, se exponen algunas orientaciones conceptuales y teóricas que sustentan el fenómeno de las ciudadanías multiculturales y se analiza las formas y lógicas de despliegue de estas mediante iniciativas locales y de políticas públicas de las diversidades; teniendo en cuenta el surgimiento de nuevas formas de ciudadanía (identidades colectivas, tácticas políticas, retóricas y discursos de demandas, modelos de institucionalización y formas de resistencia) y novedosos modos de participación ciudadana en distintas partes del mundo. Eso abre un amplio campo de posibilidades para ir estableciendo puentes de articulación teóricopráctica con el fin de replantear (o retomar) la idea de la ciudadanía intercultural, más allá de los límites de la noción de ciudadanías multiculturales, en medio de las complejidades de las sociedades actuales que se reflejan cada vez más mediante las interconexiones que tienden a establecerse entre lo local y lo global.

\section{Debates conceptuales y teóricos acerca de las ciudadanías multiculturales}

La necesidad de abrir un debate en torno a las ciudadanías multiculturales en el campo de las ciencias sociales se justifica por el surgimiento de crecientes e insistentes fenómenos sociales, económicos, políticos y culturales en un mundo global y en movimiento, que apelan a una perspectiva interdisciplinar y transdisciplinar para alcanzar su mejor aprehensión y solución (o propuestas de solución) a los problemas. En efecto, en un mundo permanentemente cambiante y con transformaciones sociales continuas dentro del marco de la globalización reinante, surgen dificultades relacionadas con la gestión de todo lo que no cabe en el marco de las lógicas tradicionales de funcionamiento del Estado y la nación: «de hecho, la ciudadanía es el principal vehículo de legitimación del EstadoNación» (Zapata-Barrero, 2003: 175). Por un lado, observamos el control y las restricciones de los flujos migratorios, igual que los tratos desiguales, excluyentes, discriminatorios y racistas, reservados a los inmigrantes y desplazados (igual que sus niños/as) en sus lugares de destino donde paradójicamente, operan los principios fundamentales de Derechos Humanos. Por otro lado, dentro de los Estados modernos, se registran una serie de situaciones que desconocen y niegan total o parcialmente las posibilidades de que otras alteridades distintas de las mayoritarias puedan participar activamente en la vida de la nación y/o contribuir a la construcción del conocimiento por medio de la pervivencia de sus sistemas de educación, saberes y sabidurías, etc. Por lo tanto, es necesario incursionar en las diversas dimensiones de la ciudadanía con énfasis en el fenómeno de las ciudadanías multiculturales.

Así mismo, precisamos que el concepto del Estado remite a una instancia socio-jurídica, siendo el Estado un espacio geográfico o un territorio sobre el cual se ejerce un poder suficiente como para establecer un orden jurídico a favor de los pueblos y comunidades de personas vinculadas a un determinado 
territorio. En este sentido, se concibe el Estado en las lógicas y dinámicas de entrelazamiento entre el Territorio, el Pueblo, y el Poder en perpetua búsqueda de mayor autonomía y soberanía. Por lo tanto, en el campo de las relaciones internacionales por ejemplo, no cabe duda que este tipo de interacción se hace más específico en torno a la soberanía ${ }^{2}$ y la frontera ${ }^{3}$ (Peñas, 2005:4). Por su parte, la noción de ciudadanía se refiere a la calidad de una persona dotada de un conjunto de derechos y deberes civiles, políticos y sociales; lo cual le otorga un estatuto socio-político que determina su sentido de pertenencia a la comunidad nacional y favorece su participación en la vida social. Es decir que la calidad de ciudadano otorga a una persona la facultad de gozar (pleno disfrute) de derechos civiles y políticos mediante los cuales puede ejercer el sufragio para elegir y ser elegido. Igualmente, le abre la posibilidad de acceder a cargos públicos y de cumplir con obligaciones frente a las instituciones de un Estado. En este sentido, la ciudadanía tiene que ver con la identidad que una persona debe manifestar cuando se relaciona con las instituciones estatales: es la única calidad reconocida por estas como legalmente válida para relacionarse con las personas; es decir que es el elemento mediador de la relación entre el pluralismo social y la unidad política estatal.

Así mismo, de la cuestión de la ciudadanía, surge el carácter pluridimensional de la ciudadanía que engloba la ciudadanía transnacional o extraterritorial; la multicultural, la multiétnica o la diferenciada; la intercultural; la plural y la universal. En efecto, en su forma más tradicional tal como lo acabamos de definir, el concepto de ciudadanía es, a la vez, esencialmente incluyente y excluyente. Es por ello que Wallerstein (1997: 11), considera que a pesar de ser un elemento estabilizador en el sistema-mundo, la ciudadanía conlleva factores de marginalización de cara a dinámicas de integración y participación. Por lo tanto, con el fin de sobrepasar estas limitaciones y contradicciones de la ciudadanía, « [...] es conveniente redefinir y redimensionar la ciudadanía, partir de las relaciones sociales de vecindad y comenzar a hablar de vecindad [multicultural e] intercultural antes de acercarnos a lo que llegue a ser la ciudadanía [multicultural e] intercultural» (Gómez, 2006). Esta necesidad se justifica por el hecho de que las sociedades no dejan de padecer transformaciones derivadas de los flujos migratorios, convirtiéndose así mismo en sociedades multiculturales e interculturales.

En esta línea de pensamiento, la noción de ciudadanía se inserta entonces en el marco de la ciudadanía universal, que considera que la ciudadanía puede incluir las nuevas circunstancias que singularizan fenómenos de nuestras sociedades actuales, de las cuales resaltamos el fenómeno de las ciudadanías multiculturales, puesto que «la ciudadanía universal traspasa las fronteras, va en busca de la

2. Para Peñas (2005: 4), la soberanía se refiere a la autoridad exclusiva de un Estado sobre la población y el territorio, como potestad para actuar en el medio internacional sin más limitaciones que aquellas con las que los Estados se han dotado a sí mismos.

3. Y, la frontera es concebida como la demarcación geográfica que delimita claramente un adentro y un afuera; o sea, esta demarcación delimita el espacio dentro del cual los deberes y derechos del Estado y de los ciudadanos tienen vigencia y fuera del cual son otros los que están dotados de ellos (Peña, 2005: 5). 
creación de un Estado Global, donde las diferencias de raza, religión y cultura no serán los obstáculos, más bien las bases sobre las cuales surgirá el nuevo orden de relaciones y de solidaridad entre los humanos» (Bercerra, 2005: 3). Así mismo, se develan las múltiples dimensiones de la ciudadanía con el fin de romper con (o socavar) la perspectiva hegemónica de la modernidad eurocéntrica con la cual se suele hablar de la relación existente entre nacionalidad y ciudadanía.

Entonces, mediante una orientación conceptual y analítica pluralista, pretendemos pensar las posibilidades de acceso y goce a/de los derechos ciudadanos multiculturales. Es en este mismo orden de ideas que, en el caso de los inmigrantes, se debe apostar por políticas universales de las migraciones en su país de destino, sin perder el apego a su país natal. Para ello, el multiculturalismo se posiciona como una herramienta potente para pensar que otros mundos son posibles. Sin duda, siendo una realidad social global que conlleva un trasfondo político y /o jurídico, el multiculturalismo se ha manifestado desde el colonialismo (en cierta medida) hasta la globalización neoliberal pasando por la modernización y el desarrollismo. Por su parte, la interculturalidad y el pluralismo cultural, en las sociedades actuales, abren el campo para pensar lineamientos y programas favorables a la participación ciudadana ${ }^{4}$, con el fin de luchar contra diversos tipos de racismo, discriminación y segregación étnico-racial y de género. En este sentido, los inmigrantes podrán ejercer su ciudadanía política en el país de destino y lograr mayor visibilidad en los intersticios de las esferas públicas del mismo; y a su vez, mantener sus nexos con su país de origen y ejercer sus derechos de ciudadano sin trabas mediante mecanismos y lógicas trasnacionales. Así mismo, surge la idea de la «ciudadanía extraterritorial» (Fitzgerald, 2000)5 porque las inmigraciones provocan tanto la convivencia (o la tensión) entre diferentes historias e identidades nacionales como la consolidación de una multiplicidad de fidelidades y lealtades a través de la experiencia trasnacional ${ }^{6}$. Así las cosas, la idea de las ciudadanías multiculturales es compatible con el concepto de la ciudadanía extraterritorial o transnacional, que permite a los inmigrantes reclamar el ejercicio de la ciudadanía en sus países de origen, aun estando fuera o físicamente ausentes del mismo.

Con el tema de la ciudadanía extraterritorial, se pretende dar la posibilidad a los emigrantes para participar formalmente en procesos políticos de sus países de origen, mediante el ejercicio del voto y el derecho a ser elegido para ocupar un cargo determinado. Sin duda, se espera que la dimensión extraterritorial de la ciudadanía conceda a los emigrantes, derechos y privilegios reservados

\footnotetext{
4. El concepto de participación ciudadana se refiere a intereses globales que hacen de la participación un punto de referencia político mediante el cual la ciudadanía exige la responsabilidad de los delegados o representantes, controla la transparencia de sus decisiones e interviene directamente en escenarios de decisión política (Velásquez, 2003: 43).

5. Este estudio de caso provee explicaciones sobre los motivos por los cuales los inmigrantes mexicanos, en Estados Unidos, quieren ser tomados en cuenta en las políticas y el desarrollo de sus comunidades de origen. El análisis tiene implicaciones importantes para propuestas discutidas en México, en torno a la extensión del derecho de voto a los emigrantes mexicanos, establecidos en el extranjero, y a su representación en el Congreso Mexicano. 
tradicionalmente a los ciudadanos que residen en el territorio nacional. Esta visión extraterritorial o transnacional de la ciudadanía da cuenta de una «apertura democrática desde abajo» (Smith, 2003: 470), mediante proyectos diaspóricos desde distintos lugares geográficos del mundo global con base en redes de migrantes que, a la vez, se acomodan y resisten a los actores del Estado centralizador. Al involucrarse en las instituciones políticas y las políticas institucionales del Estado, los emigrantes pasan de ser objetos pasivos del poder estatal o de las lógicas capitalistas a agentes activos en la construcción social de las prácticas ciudadanas de carácter transnacional o extraterritorial (Smith, 2003: 39-40). En esta lógica, el análisis de la ciudadanía extraterritorial en combinación con el estudio de la comunidad trasnacional, ayuda a acercarse a la pretendida conexión micro-macro, al mismo tiempo que supone un avance en el campo de la participación social, económica, cultural, política y ciudadana de los migrantes transnacionales.

En este orden de ideas, surgen propuestas de nuevas interpretaciones de la ciudadanía y el pluralismo que incluyen por ejemplo la ciudadanía multicultural, multiétnica o «diferenciada», entendida como « [...] la adopción de derechos poliétnicos, de representación o de autogobierno específicos en función del grupo [...]» (Kymlicka, 1996: 240-241)7. Así mismo, se evoca la necesidad de una ciudadanía multicultural que opere dentro del marco de Estados «multinacionales»y «poliétnicos» ya que «una fuente de diversidad cultural es la coexistencia, dentro de un determinado Estado, de más de una nación, donde "nación" significa una comunidad histórica, más o menos completa institucionalmente, que ocupa un territorio o una tierra natal determinada y que comparte una lengua y una cultura diferenciadas [...] Un país que contiene más de una nación no es, por tanto, una nación-Estado, sino un Estado multinacional, donde las culturas más pequeñas conforman las "minorías nacionales" [...] Obviamente, un único país puede ser a la vez multinacional (como resultado de la colonización, la conquista, o la federación de comunidades nacionales) y poliétnico (como resultado de la inmigración individual y familiar) [...] De ahí que Canadá sea multinacional y poliétnico, como los Estados Unidos [...] Por mi parte, empleo los términos cultura (y "multicultural" en un sentido diferente. Me centraré en el tipo de "multiculturalismo" derivado de las diferencias nacionales y étnicas. Como dije antes, utilizo "cultura" como sinónimo de "nación" o "pueblo"; es decir, como una comunidad intergeneracional, más o menos completa institucionalmente, que ocupa un territorio o una patria determinada y comparte un lenguaje y una historia específicas. Por tanto, un

7. Nos parece oportuno traer a colación los planteamientos de Sermeño (2000: 299-300) al referirse a la mencionada obra de Kymlicka en los términos siguientes: «en su reciente obra Ciudadanía multicultural, Kymlicka argumenta sólidamente a favor de la concesión de derechos políticos especiales a grupos de minorías dentro de un determinado Estado-nacional democrático. Según Kymlicka el reconocimiento de los derechos de minorías toda vez que se guarden los correctivos que impidan abusar de tales derechos para afirmar particularismos (nacionalismos y fundamentalismos) intolerantes y beligerantes. Para mi gusto, la lucidez de ese enfoque estriba en reconocer, como plantea Ch. Taylor, que la única manera de enfrentar los nuevos desafíos emanados de la evolución del fenómeno de la ciudadanía es aceptar que la integración social puede y debe darse a partir de la existencia de profundas diversidades, las cuales en virtud de su específica legitimidad, van a definir diversos mecanismos de integración social [… Desde esta perspectiva, el desafío de la propuesta de Kymlicka consiste en "explicar cómo coexisten los derechos de las minorías con los derechos humanos, y también como los derechos de las minorías están limitados, a su vez, por los principios de libertad individual, democracia y justicia social"». 
Estado es multicultural bien si sus miembros pertenecen a naciones diferentes (un Estado multinacional), bien si éstos han emigrado de diversas naciones (un Estado poliétnico), siempre y cuando ello suponga un aspecto importante de la identidad personal y la vida política» (Kymlicka, 1996: 26, 34, 36).

En este contexto, existen sectores poblacionales -además de ser negros, árabes, mujeres, gitanos, minorías étnicas y religiosas, grupos LGBTI- que son excluidos de la cultura ciudadana, a pesar de que poseen los derechos propios y comunes de la ciudadanía (Kymlicka \& Norman, 1997: 27). Sin embargo, Bauböck, citado por Rodríguez (2007: 25), se distancia de Kymlicka por este uso del concepto multinacional en la medida que «[...] propone deconstruir la identificación entre ciudadanía y nacionalidad y argumenta que la mejor forma de interpretar el impacto de la migración, la globalización y transnacionalización en la ciudadanía democrática es la ciudadanía cívica transnacional -en lugar de multinacional-que reconoce la superposición o coexistencia de diversas afiliaciones políticas, y la tendencia a un cosmopolitismo federal "desde abajo" (es decir, no centralizado, sino con distintos niveles y competencias, desde el nivel local al nacional)». Pues inscribiéndonos en la misma óptica que Vertovec (2001), pensamos en la necesidad de una nueva valoración y formulación de la política referente al aumento de formas de participación de las comunidades locales, movimientos sociales, minorías inmigrantes y/o étnicas, entre otros. Prueba de ello es que «[...] en los últimos años, estas cuestiones han aparecido con frecuencia en numerosas publicaciones, en las cuales se proponen nuevos conceptos de ciudadanía como punto de partida para abordar las cuestiones planteadas por las formas contemporáneas de pluralismo y las formas de exclusión que han surgido con ellas. Algunos de estos nuevos conceptos son "ciudadanía transnacional" (Bauböck, 1994a), “ciudadanía multicultural” (Kymlicka, 1995a), “ciudadanía diferenciada" (Young, 1990), "ciudadanía neorepublicana" (Van Gusteren, 1994), "ciudadanía cultural" (Turner, 1993) y "miembros postnacionales" (Soysal, 1994)» (Vertovec, 2001: 223). En la actualidad, estos términos ponen de manifiesto la necesidad de realizar estudios más profundos del concepto de ciudadanía, tal como se ha plasmado en publicaciones realizadas por numerosos académicos (por ejemplo, volúmenes elaborados por Brubaker, 1989; LaytonHenry, 1990; Bauböck , 1994; Kymlicka, 2009, 1996; Martiniello, 2001), que han expresado claramente esta necesidad de re-conceptualización de la noción de ciudadanía; y más aun cuando es necesario centrarla en un eje temático tan importante como el de la globalización y glocalización.

En efecto, «la globalización es el término para estudiar la actualidad de los cambios en el sistema mundial. Es también el proceso de redefinición que afecta a todas las partes, sin excepción, aunque tenga efectos específicos, y claro está, diferentes en cada lugar y podemos agregar: "globalización" no es solo generalización, homogenización y uniformidad sino cristalización, especificidad, variedad [...]: se trata del efecto del conjunto, del cambio de interrelaciones que modifica los elementos de la relación en su carácter individual pero también 
el conjunto: intensifican la interrelación entre lo "local y lo mundial" a costa del Estado-Nación» (Palacios, 1995: 35). Con la caída del muro de Berlín, se inicia una nueva etapa de la globalización, porque esto simboliza la caída del socialismo soviético, con lo que la bipolaridad deja de ser el eje ordenador de la vida internacional: se sincronizan las tendencias globalizantes. Además, con el 11 de septiembre 2001, se globaliza el mundo con respecto a la seguridad nacional e internacional; en este sentido, EE.UU. se interesa más en el resto del mundo debido a la lucha contra el terrorismo global, etc.

Todo ello conlleva transformaciones políticas, sociales, culturales y económicas. Con respecto a esto último, llama la atención la manera en que se aceleraron cambios profundos respeto a la globalización desde mediados del siglo XIX hasta la actualidad (revoluciones industriales, fin de la segunda guerra mundial, etc.): la globalización pasa por una fase crucial debido a la profundidad de los cambios originados por el liberalismo de mercado, ya que intensifica la aparición de nuevos actores internacionales y la interdependencia de los pueblos. Entre 1945 y 1973, se desarrollaron instituciones internacionales de cooperación financiera y comercial con el fin de favorecer la expansión del comercio. Luego, en el último cuarto del siglo XX se vive una gradual generalización del libre comercio, la creciente presencia en el escenario mundial de empresas transnacionales (multinacionales, la deslocalización de empresas del Norte al Sur, etc.) que funcionan como sistemas de producción integrados, el crecimiento y la enorme circulación de los capitales, y una fuerte tendencia a la homogeneización de los modelos de desarrollo junto con la persistencia de restricciones al movimiento de mano de obra (CEPAL, 2002).

Estas tendencias coexisten con movimientos contrarios a ellas, generándose tensiones entre el universalismo individualista, orientado a la acumulación de capital y el pluralismo de las identidades, entre el tránsito de lo local a lo global y viceversa: «al decir de Boaventura de Sousa Santos (citado en Fariñas, 2000), la relación entre lo local y lo global se puede visualizar como las dos caras de una misma moneda, en la que los fenómenos locales son globalizados y a su vez las políticas transnacionales impactan en las condiciones locales, es decir a etnias, religiones, naciones [...]» (Wiesenfeld, 2006: 47). En esta misma línea de pensamiento, el fenómeno de la globalización obliga a replantearse la eficacia de estructuras como el Estado-nación y conceptos como el de ciudadanía, en la medida que la vida política, económica y cultural de las comunidades tiende a traspasar las fronteras nacionales debido a la interdependencia entre lo local y lo global, y hace necesarias estructuras políticas, e instrumentos reguladores internacionales, para garantizar los derechos de los ciudadanos y los principios democráticos. De igual forma, las comunidades responden de diferentes maneras a esta ofensiva de la globalización; por lo cual se deben tener en cuenta las dimensiones locales a la hora de pensar en aquella. Sin duda alguna, se registran diversos planteamientos de los cuales se destaca el de Néstor García Canclini (1999), quien plantea «la imposibilidad de la existencia de lo global sin lo local, 
sin embargo cuestiona la forma de ver la relación entre lo local y lo global, cual relación entre opuestos y de ubicar el debate en los desencuentros entre las políticas de integración supranacional y la conducta ciudadana. Propone más bien incluir las mediaciones existentes entre ambos extremos, de modo de facilitar interconexiones entre actores que potencien las iniciativas sociales, legitimen las instituciones y los motiven a negociar la diversidad desde una confrontación dialógica y desde la coexistencia de diferentes concepciones. Para este autor ello supone la apertura hacia diversas experiencias culturales, es decir a la globalización desde la diferencia o al cosmopolitismo de la globalización» (1999: 48). En este marco, la noción de ciudadanía se redefine a nivel local y global, y ya no se puede asimilar únicamente al marco del Estado-nación; es decir que «la ciudadanía se desvincula del territorio y de la nación, entendida esta como comunidad cultural y/o étnica o identitaria» (Mesa, 2006: 1).

Es aquí donde el auge de los movimientos altermondialistas, alterglobalización o antiglobalización y su internacionalización es considerado como una fase importante de la globalización; lo que nos introduce a la idea de los nuevos actores de este fenómeno. Se trata de un movimiento heterogéneo formado por anticapitalistas, ecologistas, antimilitaristas, sindicatos, organizaciones no gubernamentales, etc. que promueve una globalización desde abajo. Sus antecedentes se encuentran, precisamente, en los movimientos y las redes que, a partir de los años 90, quieren dar un salto desde las políticas locales hacia la coordinación global de las resistencias contra el capitalismo neoliberal. De sus iniciativas de articulación, registramos por ejemplo el hecho que, de diciembre 2006 a enero 2007, se celebró el Encuentro Internacional para la Humanidad y contra el Neoliberalismo o Encuentro entre Pueblos Zapatistas y el Mundo promovido por el Ejército Zapatista de Liberación Nacional y la Izquierda Europea. A esa iniciativa, adhirió el Grupo Thomas Sankara (Burkina Faso) desde África. También, mencionamos las manifestaciones de Seattle en 1999, de Genes (Italia) en 2001, los Foros sociales mundial -FSM- desde 2001 (Porto Alegre) hasta 2007 (Nairobi Kenia, 20-25 de enero -) pasando por Bamako (Malí, 2006) y Mumbai o Bombay (India, 2004): son espacios y momentos privilegiados para movimientos sociales locales, regionales, continentales y mundiales que se movilizan en torno a temas distintos (por ejemplo, contra la guerra en Irak, Palestina, etc.). Con respecto a África, se observa que a pesar de la creciente presencia de los africanos en los FMS (en el primer Foro Social Mundial de Porto Alegre, a penas se contaban treinta representantes africanos de movimientos sociales; en la cuarta edición de Mumbai (2004), eran quinientos en medio de centenares de miles de representantes a nivel mundial), se tiene que reforzar su visibilidad tras un mayor protagonismo. Se va consolidando la solidaridad de las bases populares para emprender mecanismos de defensa popular en torno a las causas comunes tales como el impacto del extractivismo sobre el medio ambiente, el reconocimiento de las diferencias, la explotación de la infancia y la niñez, etc. 
Es en este contexto que surge el debate sobre las ciudadanías multiculturales para aprehender las dimensiones de la cuestión nacional e identitaria, ligada al ejercicio de los derechos en un mundo en permanente transformación. Lo anterior lleva a que, siendo la acción social el motor de las interacciones sociales, «la ciudadanía, para no ser excluyente, debe ser progresivamente desnacionalizada, desterritorializada y democratizada, y pasar a fundarse en criterios respetuosos con la dignidad humana, la igualdad de derechos y el respeto por las diferencias» (Silveira Gorski, 2000). En este nivel de análisis, pensamos que estas consideraciones teóricas y conceptuales permiten apreciar las distintas formas de expresión de las ciudadanías multiculturales en las sociedades actuales.

\section{Escenarios de expresión de las ciudadanías multiculturales en las sociedades contemporáneas}

El acercamiento crítico al concepto tradicional de la ciudadanía ${ }^{8}$, sirve para explorar los campos de posibilidades donde se manifiestan fenómenos, cuyas expresiones concretas se reflejan a través de varias dimensiones de las diversidades y contrastes culturales, socio-políticas y socioeconómicas de las sociedades actuales. Esta postura analítica permite romper con la visión del mundo donde prevalece el carácter estatocéntrico de las relaciones sociales y según la cual el mundo es un conjunto de territorios con características globalmente homogéneas donde opera el principio de la universalidad de los derechos humanos asociado a la primicia universal de igualdad. Por lo cual, la pertinencia de algunos fenómenos sociales (o realidades sociales), capta nuestro interés investigador a la hora de pensar las ciudadanías multiculturales y sus (posibles) alcances en escenarios locales, nacionales, internacionales y globales.

Migraciones y desplazamientos. El binomio migraciones y desplazamientos nos invita a hacernos algunos interrogantes como: ¿Hasta qué punto estas migraciones y desplazamientos forzados interregionales e internacionales son compatibles con la construcción de la ciudadanía multicultural? y ¿En qué medida este concepto de ciudadanía multicultural refleja algunos de los retos que las migraciones actuales y los desplazamientos afrontan en las sociedades modernas de acogida? Ambas preguntas obligan a reflexionar sobre la conexión entre la nacionalidad y la ciudadanía con el fin de evaluar el rol de estas migraciones en la construcción de las ciudadanías multiculturales. En efecto, las migraciones internas e internacionales, igual que los desplazamientos forzados constituyen un desafío real a la ciudadanía en la medida que plantea la necesidad de re-visitar los conceptos de multiculturalismo, interculturalidad y pluralismo9, con el propósito de reinventar la ciudadanía intercultural y plural, 
que desemboque en la ciudadanía universal con el fin de prevenir los guetos. Así, consideramos que más allá de las limitaciones de las políticas migratorias, se deben elaborar políticas públicas de extranjería (Akindés, s/f.) en los países de acogida, con el fin de encontrar y establecer fórmulas flexibles, como la ciudadanía multicultural, favorable para la extensión de los derechos, a todos los residentes, mediante el acceso a la ciudadanía formal y la atribución de la nacionalidad del país de residencia; las cuales deben hacerse más accesibles cuando son reclamadas. Frente a las fronteras territoriales y su blindaje, la noción de ciudadanía multicultural nos parece una de las formas más adecuadas para enfrentarse con los retos de las migraciones y desplazamientos, en pleno siglo XXI, ya que la ciudadanía multicultural transgrede y traspasa las limitaciones impuestas a la libre circulación de las personas. Esta transgresión multicultural, asociada a la noción de «ciudadanía universal» ${ }^{10}$ nos parece una de las formas más adecuadas de abordar los retos de las migraciones en pleno siglo XXI.

Transnacionalismo y diásporas. Las relaciones que se establecen entre las migraciones y sus diásporas, mediante el transnacionalismo, implican muchas comunicaciones e interacciones continuas y permanentes que conectan los pueblos y las instituciones a través de las fronteras de los Estados-Nación. En este contexto, estos Estados-nación son concebidos como terrenos móviles que integran múltiples escalas desde lo local hasta lo global, y aquellas intermedias; situación que exige precisar el significado del concepto diáspora. Por lo tanto, «diáspora» se refiere a los grupos de personas -habitualmente con características étnico-raciales- que se han reubicado en un territorio determinado (lugar de destino), después de haber sido trasladados desde su lugar de origen mediante las migraciones: forman así comunidades diaspóricas que son trasplantadas a partir de distintas conexiones con su territorio primigenio (la tierra de origen). Por lo cual, el concepto de diáspora al que se hace referencia en este trabajo coincide con el de la «nueva diáspora» al que, partiendo de los planteamientos de Carter (2003), se refiere Sow (2007: 139-140), cuando afirma que «las "nuevas diásporas africanas" de las que Carter llama nuestra atención son aquellas que permiten entender la paradoja de la pertinencia; aquellas sustentadas por las redes sociales y culturales, los lazos múltiples y los lugares híbridos que van desarrollándose con o sin el rumbo de la mundialización. Esas redes, lazos y lugares emergen en contextos novedosos que siguen a menudo los circuitos de la cultura global, de la sociedad civil, de las organizaciones religiosas, etc. [...] Todas estas diásporas tienen en común el hecho de estar compuestas por una "gente de paso" alejada de la noción de "comunidades territorialmente fijas". No tienden tampoco a ser totalmente nómadas. Cada vez más, esa gente crea e inventa nuevos pasos translocales y transculturales. Es decir, son grupos móviles que hacen mover tanto las fronteras físicas como el monolítico concepto del Estado-nación $[\ldots] »$. 
Y, no sobra traer a colación la definición de la noción de diáspora que, en palabras de Wenden (2004: 83), deriva «[...] del latin spiro: yo siembro, que antiguamente se usaba para referirse a las comunidades judías localizadas fuera de Palestina, desde hace algunos años ha pasado a formar parte del vocabulario de las ciencias sociales. Sirve para describir un estado de dispersión que se convierte en modo de existencia y que tiene como propósito crear, desde el exterior, redes transnacionales destinadas a borrar a veces las fronteras de los Estados, y a definir las pertenencias [...]». En este orden de ideas, la noción de ciudadanía multicultural alimenta la apuesta para que las diásporas africanas, en el mundo en general y en Colombia en particular, puedan ir convirtiéndose en unos puntos de encuentro para el diálogo intercultural y político con África (Wabgou, 2010). De igual manera, la pretensión para impulsar acercamientos entre pueblos africanos, suramericanos y asiáticos (Wabgou, 2013b), se nutre de la idea de la ciudadanía multicultural teniendo en cuenta estos pueblos como ciudadanos multiculturales que, desde distintos escenarios, construyen formas y dinámicas de diálogo y cooperación horizontal (fuera del margen de la verticalidad de los diálogos Norte/Sur), diferentes de las más tradicionales que suelen ser marcadas por la racionalidad eurocéntrica.

Conocimientos y saberes. La noción de ciudadanías multiculturales contempla también la necesidad de imprimir una dimensión inter y transdisciplinar a las áreas y los escenarios de conocimiento. Aquí, recurrimos a la dimensión postcolonial incorporada en la visión de interculturalismo de Walsh (2012, 2010, 2009, 2006, 2005, 2002), para explicar la forma como la idea de las ciudadanías multiculturales ayuda a democratizar el campo de conocimientos y saberes. Esta perspectiva es adecuada y pertinente para debates y reflexiones en el campo de las ciencias sociales y los estudios étnicos (sobre todo indígenas y afrocolombianos), porque desvela la validez de los saberes locales, amenazados por los saberes hegemónicos impulsados por la globalización capitalista. Además, denuncia la «colonialidad del saber» (Quijano, 2000a; 2000b), que fomenta el encubrimiento y/o la negación de ciertas formas de conocimiento propio y distinto al hegemónicamente imperante; e impulsa el espíritu crítico sobre las realidades sociales y desde lo local, por medio de la deconstrucción científica y reconstrucción emancipadora en el marco de los estudios poscoloniales. Es aquí donde la noción de ciudadanías multiculturales ayuda a concebir estos saberes como expresiones de las realidades sociales que interrogan el orden establecido y jerarquizado de los concomimientos; el cual suele excluir las minorías étnicas, los inmigrantes, los desplazados, entre otros, de las nuevas formas de uso y apropiación de las TIC (Tecnologías de la Información y la Comunicación). Por lo cual, se debe buscar incorporar las perspectivas de género, diversidad étnica y sexual (orientación sexual -LGBTI-) en las formas y lógicas de acceso al conocimiento, incluyendo en los currículos de educación ${ }^{11}$ básica, media y superior de todas las áreas del saber, el enfoque de derechos étnicos y el respeto a todas las diferencias de clase, edad, etnia, género, orientación sexual, 
discapacidad, origen regional y rural/urbano, desplazamiento y otras; lo que implica la inclusión de los saberes tradicionales de los pueblos en los programas curriculares. En este orden de ideas, es oportuno el uso de la perspectiva teórica poscolonial que denuncia la subalternización epistémica del «Otro»y la producción de imaginarios sobre el «Otro»; mientras defiende la legitimidad de la producción de conocimientos y saberes propios y locales (Castro-Gómez, 2005; Mignolo, 2002). Lo que se plantea aquí es la necesaria descolonización de los saberes derivados de las ciudadanías multiculturales en la medida que los pueblos autóctonos (o civilizaciones) de África, Asia, América del Sur y el Caribe resisten a la ofensiva neoliberal de ser transformados en objeto de museo.

Desarrollo propio. En el marco de las dinámicas de relacionamiento del ser humano con la naturaleza, las cosmovisiones de poblaciones tradicionales (como los pueblos indígenas, africanos y afros, entre otros) apuntan al respeto del entorno natural y el medio ambiente. De allí derivan todas las lógicas de construcción y alcance del desarrollo propio (o progreso). Así las cosas, el ser humano progresa en armonía con la naturaleza; o sea que el progreso no puede desconectarse de la naturaleza o violentarla. Por lo tanto, estas visiones del mundo son tan particulares, como importantes, a la hora de pensar en las ciudadanías multiculturales, puesto que invitan a la humanidad a tomar posturas críticas de la modernidad, junto con sus derivas desarrollistas y sus correlatos de modelo económico de producción y consumo. Surgen entonces interrogantes al concepto de «desarrollo» desde el enfoque de la acumulación del capital y bienes, igual que la relación social mediada por el poder económico. De igual manera, estas cosmovisiones invitan a la humanidad a tomar consciencia de la importancia de proteger las riquezas naturales mientras apuestan, desde la perspectiva de las ciudadanías multiculturales, por formas alternativas de desarrollo, en términos de desarrollo propio o progreso con rostro humano.

En este orden de ideas, el concepto del «buen vivir» o «vivir bien» toma una gran relevancia cuando se refiere a la terminología Sumak Kawsay que refleja la cosmovisión ancestral de los pueblos indígenas ubicados principalmente entre Ecuador, Perú y Bolivia, y que hablan la lengua quechua, una de las familias lingüísticas más extendida de la zona con aproximativamente 10 millones de quechuahablantes. En efecto, insistimos en la importancia del papel que deben jugar las cosmovisiones indígenas en los debates actuales volcados hacia el futuro de nuestro planeta, apostando por la búsqueda de alternativas a distintos modos de vida y producción imperantes y derivados de la modernidad. Esa postura afianza los planteamientos de Quijano (2012: 54), según los cuales «América Latina y la población "indígena” ocupan, pues, un lugar basal, fundante, en la constitución y en la historia de la colonialidad del poder. De allí, su actual lugar y papel en la subversión epistémica/teórica/histórica/estética/ ética/política de este patrón de poder en crisis, implicada en las propuestas de des/colonialidad global del poder y del Bien Vivir como una existencia social alternativa». 
La necesidad de precisar el sentido de la noción del «buen vivir» nos lleva a referirnos a Houtart (2011: 224-235), quien con base en el trabajo de varios autores, realiza una exploración semántica de la noción del Sumak Kawsay (Ecuador) o el Suma Qamaña (Bolivia). La revisión conceptual propuesta por el autor, sirve para afirmar que el término Sumak Kawsay «implica la satisfacción de las necesidades, una calidad de vida, amar y ser amado, paz y armonía con la naturaleza, protección de la cultura y de la biodiversidad»; la idea se refiere a «una serie de derechos y garantías sociales, económicas y ambientales». Por su parte el Suma Qamaña de los aymaras de Bolivia, «significa la complementariedad social, rechazando la exclusión y la discriminación y buscando la armonía de la humanidad con la "Madre Tierra", respetando las leyes de la naturaleza. Todo eso constituye una cultura de la vida, en oposición a la cultura de la muerte [...] significa "convivir bien" (y no vivir mejor que los otros). No se trata solamente de bienes materiales, sino también espirituales. Se debe primero satisfacer las necesidades locales, en convivencia con la Madre Tierra y en reciprocidad y afecto con los demás [...] Es una espiritualidad que implica la paz y la construcción de una "tierra sin mal"». En ambos casos (Sumak Kawsay y Suma Qamaña), el ejercicio teórico-práctica (aplicación conceptual a la realidad social) apunta a la reivindicación de una «reintegración de la naturaleza en la historia, como inherente al ser social»; en otras palabras un «arte de vida» que se convierte en una «crítica del modelo actual de desarrollo y una llamada a construir una calidad de vida que incluye, tanto a las personas como a la naturaleza». Y, en el caso particular del Sumak Kawsay, el ejercicio se vuelve más atractivo cuando, desde la perspectiva feminista, la noción cobra mayor relevancia con la introducción del concepto de «economía del cuidado humano» porque «allá se recupera la idea de la vida como eje y categoría central de la economía».

En este punto, consideramos que las funciones de los conceptos de Sumak Kawsay (Ecuador) y Suma Qamaña en el contexto actual de las sociedades modernas, son claves porque abren espacios de articulación de las ciudadanías multiculturales, al permitirnos plantear una crítica a la modernidad que conlleva exclusiones en el marco de un modelo económico de producción y consumo exacerbado, cuya racionalidad suele ser meramente instrumental, puesto que opera en función de lógicas y dinámicas mercantilistas que defienden la idea de desarrollo asociado al crecimiento; esto es, un crecimiento sin fin. Es en este sentido que Quijano (2012), con base en el pensamiento tradicional de los pueblos indígenas, asume una crítica frontal a la idea de «desarrollo» al situar el «Bien vivir» entre el «desarrollo» y la «des/colonialidad del poder»; es decir, al romper con la hegemonía del eurocentrismo en el debate que, hasta la Segunda Guerra Mundial, llevaba a plantearse el «desarrollo» en relación con el Estado/Nación en América Latina, por lo cual, coincidimos con Houtart (2011: 236), en que «el capitalismo benevolente es incompatible con el "buen vivir"». Además, resaltamos las repercusiones políticas de la noción de Sumak Kawsay en Ecuador donde ha sido introducido en la Carta Magna ecuatoriana de 2008 y se ha retomado el concepto por medio del « [...] Plan Nacional para el Buen 
Vivir 2009-2013. Se trata entonces de una idea central en la vida política del país. Por esta razón es importante analizar su contenido, su correspondencia eventual a la noción de "Bien Común de la Humanidad", desarrollada en el seno de la Organización de la Naciones Unidas, y sus posibles aplicaciones en las prácticas internacionales. La pertinencia de esta referencia está reforzada por el conjunto de las crisis provocadas por el agotamiento del sistema capitalista» (Houtart, 2011: 224).

Por otra parte, desde la visión de las comunidades negras y pesqueras del Pacífico colombiano, consideramos que la idea de ciudadanías multiculturales abarca las dinámicas de «desarrollo propio» cuando en las comunidades, se evidencia el afán de sectores poblacionales que viven básicamente de la agricultura y pesca tradicional en zonas rurales, para construir culturalmente una serie de relaciones muy ligadas a la estructura social tradicional y al entorno natural (su «hacer productivo»). Eso se refleja mediante sus formas de entender y vivir el desarrollo, pese a la ofensiva de la globalización capitalista y las acciones impositivas y desintegradoras de las colectividades por parte del Estado colombiano que no deja de promover procesos económicos modernizantes en estas zonas, dando la espalda al «desarrollo propio» asociado a formas alternativas (o simplemente distintas) de concebir el mundo y el desarrollo.

Y en África, persisten prácticas tradicionales de producción fundamentadas en el pensamiento africano (filosofía) del Muntu que defiende las ideas de amor a la naturaleza y a lo humano. Se trata de una filosofía o un pensamiento de fraternidad entre los seres y los entes de la creación, construyendo una cosmovisión del mundo en mitos, estética, derecho, técnica, medicina, organización social, etc. Esta filosofía es propia a los integrantes de la gran familia étnica y lingüística (suahili) ${ }^{12}$ de los bantúes que se ubican esencialmente en el África Oriental y Central y que se constituyen en un escenario significativo de expresión y acción de las ciudadanías multiculturales. De aquí, pensamos que la dimensión de las ciudadanías multiculturales engloba también a las nuevas formas de reivindicaciones lingüísticas y de políticas lingüísticas en marcha a nivel continental, como las promovidas desde la Unión Africana (UA) que ha convertido el suahili en una lengua oficial del continente, con el propósito de convertirla en una lengua panafricanista en el futuro; lo que, desde nuestra perspectiva, obedece a las lógicas de las ciudadanías multiculturales.

Educación inclusiva. Esta educación se refiere a un proyecto (o un proceso) educativo que busca orientarse hacia la atención de las necesidades de

12. Retomamos las precisiones aportadas en un trabajo anterior (Wabgou, 2008: 37) acerca de esta lengua, en los términos siguientes: «también conocido como kisuahili, el suahili comenzó a expandirse mediante extensas interacciones entre africanos de la región oriental con los del Océano Índico tal como las islas Comores y Madagascar; teniendo en cuenta que el comercio y las migraciones ayudaron a difundir la lengua entre naciones del sureste africano tales como Malawi y Tanzania. Es discutible cuánta gente habla suahili como primera o segunda lengua puesto que las más conservadoras estimaciones hablan de 45 millones mientras que otras señalan unos 60 millones de personas en África del este y central, particularmente en Tanzania, Kenia, Uganda, Somalia, Mozambique, Malawi, Ruanda, Burundi, Zambia y la República Democrática del Congo. En la actualidad, el suahili es una lengua oficial de la Unión Africana (UA) porque se considera que es parte de la identidad africana y se espera que en el futuro se convierta en "una lengua pan-africana". Las otras lenguas oficiales de la Unión Africana son el inglés, el francés, el árabe, el portugués y el español». 
aprendizaje de personas en edades de la adultez, juventud, infancia y niñez, con enfoque diferencial volcado en aquellas que presentan vulnerabilidades en términos de exclusión social, discapacidades y marginación, entre otras. En un sentido más amplio, la expresión «educación inclusiva» alude a una respuesta educativa alternativa que pretende impulsar transformaciones progresivas en los sistemas tradicionales de educación, apostando por mecanismos de educación de calidad a todas las personas por igual y una mayor sensibilidad (y apertura) a las diversidades étnico-raciales y de género, entre otras. Es en este orden de ideas que, en un trabajo anterior (Wabgou, 2013c), abordamos el tema de la inclusión de las personas afrodescendientes en la educación superior colombiana, puesto que la educación superior juega un rol estratégico en el proyecto de progreso económico, social y político con el que está comprometido Colombia.

En efecto, como proyecto y proceso, la educación inclusiva se nutre del concepto de la interculturalidad que deriva del multiculturalismo ${ }^{13}$; el cual opera mediante diversas políticas públicas de las diversidades y las diferencias y se conecta de múltiples formas con articulaciones de la alteridad. Es por ello que la idea de las ciudanías multiculturales, en el campo de la educación inclusiva, abarca al nativo/a, desplazado/a o inmigrante negro/a, chino/a, latino/a, hombre/mujer, empresario/a, pobre, etc. Ahora «cuando se dice, por ejemplo, que una escuela es "multicultural" se puede estar diciendo que en ese centro escolar están escolarizados españoles y extranjeros, autóctonos e inmigrantes, gitanos y no gitanos (payos). Se está indicando con ello que es relevante la presencia de minorías étnicas, que hay una diversidad cultural notable, etc. Pero se puede estar diciendo - y así ocurre en países como Inglaterra de amplia aplicación del multiculturalismo - que ese centro escolar responde a las normativas y orientaciones multiculturalistas, tratando de superar los curriculums ocultos y etnocéntricos, organizando la escuela para que se vean reflejadas las distintas expresiones culturales, contratando a profesores bilingües y biculturales, etc.» (Giménez, 2003: 4). En este orden de ideas, es pertinente la noción de la interculturalidad que promueve la convivencia en la diversidad, con base en los principios de igualdad y diferencia, interacción constructiva o positiva. Así, la perspectiva de la interculturalidad busca desarrollar una interacción entre personas, conocimientos y prácticas culturalmente diferentes para garantizar la transformación de las relaciones sociales, igual que la transformación de las relaciones sociales y de las estructuras e instituciones públicas. Así mismo, de acuerdo con Giménez (2003: 4), « [...] la perspectiva intercultural está surgiendo básicamente tras la constatación de los límites, fracasos y errores en el campo del multiculturalismo, lo cual no debe ocultar los méritos y aportaciones de la

13. De todos modos, el multiculturalismo y la interculturalidad se identifican como dos modalidades dentro del pluralismo cultural, "[…] en el sentido de que tras unas primeras décadas en que la propuesta sociocultural pluralista de los años sesenta se concretó en elaboraciones y políticas multiculturalistas, desde finales de los ochenta han venido tomando fuerza los planteamientos interculturalistas en campos tan diversos como la educación, mediación, comunicación, trabajo social, filosofía, etc. [...] Por ello, y porque ambos planteamientos tienen en común los pilares del edificio propuesto desde el pluralismo cultural (valoración positiva de la diversidad, critica de las propuestas de pérdida o resta cultural, igualdad y no discriminación por razones de diferenciación etnocultural de las personas, respeto al diferente, etc.) es por lo que consideramos más ajustado - y clarificador- ver el multiculturalismo y la interculturalidad como concreciones sucesivas del paradigma pluralista" (Giménez, 2003: 3 \& 4). 
perspectiva multiculturalista». Es aquí donde identificamos y evidenciamos la educación inclusiva como un espacio de expresión, acción y articulación de las ciudadanías multiculturales aun si abogamos por la interculturalidad $\mathrm{y}$, en un alto grado, el pluralismo cultural en las sociedades actuales porque es la vía a seguir para emprender lineamientos y programas favorables a la solidaridad, integración y cohesión social que son necesarias para la construcción y consolidación de Estados y naciones multiétnicos/as. Es por ello que consideramos que la educación propia, se inserta en el marco de las lógicas y dinámicas de la educación inclusiva. Uno de los ejemplos más cercanos a este tipo de educación es la educación indígena, actualmente en desarrollo en el departamento del Cauca (Colombia), y que además, se posiciona en resistencia a la ofensiva del sistema educativo promovido por el Estado colombiano; tal como lo evidencia Galeano Lozano (2013), a la hora de estudiar las Políticas Públicas de Educación Indígena construidas por el consejo Regional Indígena del Cauca -CRIC-1974-2012.

Extractivismo y resistencias sociales. Este escenario de manifestación de las ciudadanías multiculturales, abarca los movimientos sociales e identidades étnicas que, ante los daños causados por la extracción de recursos mineros como el carbón, el petróleo, el gas, etc. al planeta tierra, y que adoptan actitudes de rechazo al extractivismo (formas exacerbadas de extracción de los recursos). Es decir que, se escuchan cada vez más voces desde sectores de las poblaciones del mundo que perciben, con intensidad creciente, que lo que está en juego ahora por medio del extractivismo no es sólo su pobreza (o pauperización) sino, nada menos que su propia sobrevivencia. Entonces, como expresión de solidaridades de/entre los excluidos, defienden la idea de dejar el petróleo bajo tierra y mar porque si bien su explotación trae ganancias y beneficios económicos, el ejercicio de sus derechos culturales y cosmovisión (como parte integral del mundo) les hace defender la Madre Tierra que padece una serie de transformaciones desastrosas relacionadas con el calentamiento climático, la deforestación, el deterioro del ecosistema, entre otros. Esta idea pone en juego la conexión entre el extractivismo y los conflictos sociales (y armados) en el mundo en general y en África, Asia, América Latina y el Caribe, en particular. La ilustración de casos en África y América Latina permite identificar por un lado, las resistencias de los pueblos Ijaw ubicados en el Estado de Delta (sureste de Nigeria) y los pueblos Ogoni en el Estado Rivers (sureste de Nigeria). Hace más de dos decenios que estos grupos étnicos se enfrentan tanto con las lógicas (y acciones) extractivistas del Estado federal nigeriano como de sus socios (dos de las más grandes compañías petrolíferas del mundo); esto es, Shell y Chevron (Texaco).

Por otro lado, encontramos el caso de los indígenas del parque Nacional Yasuni (en Ecuador), quienes, con el apoyo de sectores la sociedad civil, lograron que el gobierno aceptara dejar bajo tierra los 850 millones de barriles de petróleo, por respeto de los derechos indígenas; y con el propósito de mantener intacta 
la biodiversidad y evitar emisiones de aproximativamente 410 millones de toneladas de gases que derivarían de la eventual extracción de petróleo. Esta decisión ha suscitado reacciones positivas y entusiastas en el mundo en general, y en los sectores del activismo o militancia ambientalista, en particular. El efecto alentador de esta decisión es más fuerte e impactante cuando observamos que se han ido estableciendo alianzas de solidaridad entre estos pueblos indígenas de Ecuador y autóctonos de Nigeria para consolidar estrategias de lucha común contra todas las formas de explotación a ultranza de los recursos naturales. Lo que da lugar al concepto de Yasunización que, desde una perspectiva glocal, está cada vez más presente en los discursos de ambientalistas y ecologistas. En este orden de ideas, aceptamos los planteamientos de Temper et al. (2003: 9), según los cuales la «Yasunizacion conlleva una perspectiva "glocal" que ha sido capaz de trascender y unificar luchas de carácter local y universal para la justicia medioambiental; igual que crear espacios democráticos de acción defensiva y proactiva. El concepto pone énfasis en la necesidad de realizar cambios estructurales en la economía mundial y aplicar la justicia restaurativa más que la redistributiva; de igual manera, enfatiza en la idea según la cual la soberanía y la acción directa proporcionan un anteproyecto para una alternativa al desarrollo que pueda orientar los términos del debate sobre el clima hacia nuevos modelos $[\ldots]$ ».

\section{Revisitando la ciudadanía intercultural desde las ciudadanías multiculturales: reflexiones que hilan conclusiones}

En este artículo, hemos intentado aportar elementos de reflexión acerca de la noción de ciudadanías multiculturales, en el marco de los procesos de construcción de las sociedades actuales, y algunas de sus diversas formas de expresión, lo que nos ha llevado a hacer planteamientos en torno a las posibilidades de retomar la idea de las ciudadanías interculturales en las sociedades modernas y contemporáneas. En efecto, pensar las ciudadanías multiculturales abre la posibilidad de concebir políticas públicas, con perspectivas más incluyentes, $\mathrm{y}$ apelar a una perspectiva interdisciplinar y transdisciplinar en las ciencias sociales, para alcanzar una mejor comprensión de los hechos, o fenómenos sociales, cuya complejidad es cada vez más manifiesta y acentuada en nuestras sociedades. En este contexto, la noción de ciudadanías multiculturales se inserta en el marco de la ciudadanía universal, que considera que la ciudadanía puede incluir las nuevas circunstancias que singularizan fenómenos de nuestras sociedades actuales. Es en este mismo paquete de ciudadanía universal, donde cabe la idea de la ciudadanía intercultural, teniendo en cuenta los debates en torno a la interculturalidad, la multiculturalidad, y el multiculturalismo en las sociedades modernas en general (Wabgou, 2013a: 91-95); sociedades que se hallan en permanente y creciente transformación. 
Recordamos que la multiculturalidad se presenta como una condición de hecho, en donde confluyen diferentes entramados culturales (étnicos) con o sin reconocimiento jurídico o político de esta multiplicidad cultural. Por ejemplo, la experiencia colombiana ha demostrado cómo, aunque haya existido una tardía visibilidad y reconocimiento del hecho multicultural por parte del Estado, siempre este país ha sido multicultural. Esta multiculturalidad debe ser diferenciada del multiculturalismo, como políticas concretas a favor de la multiculturalidad dentro del marco jurídico o del derecho. Sin embargo, siendo un hecho de orden jurídico y político, el multiculturalismo no es único ni estático; se debe entender desde una perspectiva meta-cultural, es decir, como una articulación histórica y contingente (no estática), asociada a un régimen de verdad que se corresponde con las relaciones de saber y poder. Entonces, es cierto que el multiculturalismo y la interculturalidad se identifican como dos modalidades dentro del pluralismo cultural, que alimentan la concepción multicultural de la ciudadanía y que invitan a que los actores políticos puedan elaborar políticas públicas más flexibles y abiertas; es decir las políticas públicas de las diversidades (Roth \& Wabgou, 2009). En definitiva, estas políticas deben ayudar a fomentar el conocimiento mutuo que permite frenar la tendencia de rechazo o del miedo destructivo del «otro», reducir la hostilidad espontánea respecto al desconocido y al extraño, y atenuar la antipatía natural hacia lo diferente y lo diverso.

En efecto, la identificación de formas de expresión de las ciudadanías multiculturales en las sociedades actuales, nos ha llevado a explorar escenarios donde se evidencian sus manifestaciones, tales como los espacios que registran el auge de los movimientos altermundialistas, alterglobalización o antiglobalización y su internacionalización como una fase importante de la globalización. De igual manera, el proceso de construcción de ciudadanías multiculturales se da porque existe una interrelación entre lo «local» y «lo global»; esa conexión permite imprimir una perspectiva glocal a los discursos y acciones de activistas ambientalistas y ecologistas que buscan resaltar algunas especificidades locales en medio de debates y reflexiones sobre problemáticas sociopolíticas, económicas y culturales derivadas de la ofensiva homogenizante de la globalización.

Es por ello que el extractivismo se constituye por ejemplo en uno de estos escenarios donde se expresan resistencias sociales nutridas de cosmovisiones de los pueblos autóctonos como los pueblos ijaw y ogonie en Nigeria, igual que los pueblos indígenas del parque Natural de Yusani (Ecuador). Este escenario desvela dinámicas de consolidación de las ciudadanías multiculturales que abarcan los movimientos sociales e identidades étnicas que protagonizan reivindicaciones para no explotar los recursos petrolíferos, esto es, dejar el petróleo bajo tierra y mar. Ante los daños causados por la extracción de recursos mineros (carbón, petróleo, gas, etc.), explotación y extracción de los bosques, las cosmovisiones de los pueblos autóctonos con respecto al planeta tierra, la «madre tierra» y el entorno natural se posicionan como una punta de lanza para luchar por una 
sociedad más armoniosa con la naturaleza. En este sentido y desde la perspectiva de las ciudanías multiculturales, hemos registrado el «muntu» (respeto a la naturaleza), el Sumak Kawsay (el «buen vivir» o «vivir bien») y el Suma Qamaña (el «convivir bien») como propuestas de principios éticos de vida a sabiendas de que el «vivir bien» implica « [...] el acceso y disfrute de los bienes materiales en armonía con la naturaleza y las personas. Es la dimensión humana de la realización afectiva y espiritual. Las personas no viven aisladas, sino en familia y en un entorno social y de la naturaleza. No se puede Vivir Bien, si se daña la naturaleza» (Albo, 2011: 136).

De la misma forma, la apuesta está dirigida a una explotación forestal participativa, en simbiosis con los conocimientos y las culturas ancestrales de los autóctonos, que busca manejar los productos forestales (leña de fuego, madera, etc.), por medio de métodos de diversificación e intensificación que combinan y refuerzan a su vez las dimensiones socio-económicas y medioambientales de las actividades forestales. Además, articulando los saberes tradicionales de los grupos étnicos y el medio ambiente, precisamos que ha llegado la hora de promover sistemas sostenibles de explotación de los recursos naturales en general y forestales en particular en el «Sur» puesto que nuestra proyección hacia el futuro debe ir de la mano con las condiciones sostenibles de vida en zonas rurales. Lo anterior, gracias a la gestión participativa de los recursos forestales y el sistema tradicional de silvicultura campesina, favorables al buen manejo y la conservación de los recursos forestales. No nos cabe la menor duda que, estas iniciativas vislumbran posibilidades de acogida de las mencionadas nociones tradicionales indígenas y autóctonas en el pensamiento político de las sociedades actuales; impulsando así la puesta en escena de las ciudadanías multiculturales.

Aparte de las articulaciones entre lo local y lo global por medio de las cuales se expresan diversas formas de ciudadanías multiculturales, otros escenarios de puesta en marcha de las ciudadanías multiculturales que hemos contemplado en este documento son las articulaciones transnacionalismo y diásporas; conocimientos y saberes; desarrollo propio y desarrollo a secas; educación inclusiva y sistema tradicional (y formal) de educación; migraciones (internas e internacionales) y desplazamientos forzados. Además, las ciudadanías multiculturales son concebidas como nuevos actores de los escenarios políticos a nivel nacional e internacional que cuestionan el concepto tradicional de la ciudadanía. En esta perspectiva, se plantea la necesidad de pensar las ciudadanías multiculturales y re-visitar la ciudadanía intercultural con base en los conceptos de interculturalidad y pluralismo.

En definitiva, los alcances de las ciudadanías multiculturales que hemos registrado y analizado en el presente trabajo, abren posibilidades de apostar por la construcción de la ciudadanía intercultural, teniendo en cuenta que la noción de interculturalidad promueve la convivencia en la diversidad, con base 
en los principios de igualdad y diferencia, interacción constructiva (o positiva) e interdependencia. La perspectiva de la interculturalidad busca desarrollar una interacción entre personas, conocimientos y prácticas culturalmente diferentes para garantizar la transformación de las relaciones sociales, igual que la transformación de las relaciones sociales y de las estructuras e instituciones públicas. En este sentido, la interculturalidad se diferencia del multiculturalismo en la medida que se presenta como un proyecto que cuestiona los diversos multiculturalismos al criticarles, porque considera que éstos se quedan en el reconocimiento de la diferencia en el marco de una jerarquía de poderes. Es más, «el enfoque intercultural tiene un mayor alcance analítico y normativo que el multicultural para gestionar la diversidad en Estados plurinacionales y pluriculturales. Si bien ha sido pensando en y desde América Latina, sus postulados tienen mayor potencial de generalización que el multiculturalismo: permite dar cuenta de un rango más amplio de fenómenos de diversidad cultural a partir de la distinción entre culturas dominantes/subalternas, más que mayoritarias/minoritarias, y concebir la identidad colectiva en términos relacionales. Posibilita ir más allá de la tolerancia, la coexistencia y la igualdad formal entre culturas, para favorecer el respeto, la convivencia y la igualdad sustancial. Propende por una igualdad y una justicia sustantiva, más que formal, entre culturas. Favorece una relación de aprendizaje mutuo [...]» (Cruz Rodríguez, 2013: 126).

Por todo lo anterior, precisamos que la puesta en escena de la interculturalidad es uno de los mayores retos a los cuales se enfrentan los Estados y la mayoría de las sociedades modernas, porque plantea la posibilidad de superar los límites de las instituciones estatales con el fin de incluir a una mayor parte de las personas y la sociedad civil (grupos étnicos, ONG locales, sindicatos, academia, etc.), en los procesos de elaboración de las políticas favorables a una mayor interacción social y tolerancia. En este sentido, consideramos que debe apostar por la interculturalidad y el pluralismo cultural, en las sociedades actuales, para emprender lineamientos y programas favorables a la solidaridad, integración y cohesión social, que son necesarias para la construcción de la ciudadanía intercultural, con el fin de impulsar procesos viables y sostenibles de consolidación de las naciones multiétnicas y Estados plurinacionales y pluriculturales. 


\section{Referencias bibliográficas}

Akindès, F. s/f. Migrations, politiques publiques de l'«étranger» et citoyenneté en Afrique de l'Ouest, Documento PDF, disponible en http://www.pdfgeni.com/book/sociologieafrique-de-l--ouest-pdf.html Consultado el 22 de abril de 2014.

Albo, X. 2011. Suma Qamaña=Convivir bien. ¿Cómo medirlo? en Ivonne Farah H. \& Luciano Vasapollo (coords.), Vivir bien: ¿Paradigma no capitalista? Pp.133-144. La Paz: CIDES-UMSA, Sapienza Universitá di Roma, Oxfam.

Bauböck, R. 1994. Transnational Citizenship: Membership and Rights in International Migration. Elgar: Aldershot.

Becerra, H. 2005. Migración y ciudadanía universal, en Boletín Foro Nacional para las Migraciones en Honduras-FONAMIH-, № 19: 1-3.

Brubaker, W. 1989. Immigration and the Politics of Citizenship in Europe and North America. New York: University Press of America.

Castro, S. 2005. La poscolonialidad explicada a los niños, Colección Jigra de Letras. Popayán: Editorial Universidad del Cauca; Instituto Pensar, Universidad Javeriana.

CEPAL. 2002. El carácter histórico y multidimensional de la globalización, en CEPAL, Globalización y Desarrollo, Primer capítulo. Disponible en: http://repositorio.cepal. org/bitstream/handle/11362/2724/S2002024_es.pdf?sequence=2 Consultado el 21 de abril de 2014 .

Cruz, E. 2013. Pensar la interculturalidad: Una invitación desde Abya-Yala/América Latina. Quito: AbyaYala.

Fitzgerald, D. 2000. Negotiating Extra-Territorial Citizenship: Mexican Migration and the Transnational Politics of Community. La Jolla, CA: Center for Comparative Immigration Studies, UCSD.

Galeano, M. 2013. Políticas Públicas de Educación Indígena construidas por el consejo Regional Indígena del Cauca -CRIC-1974-2012, Tesis de Maestría en el Programa de Maestría en Políticas Públicas, Facultad de Derecho, Ciencias Políticas y Sociales, Departamento de ciencia Política. Universidad Nacional de Colombia, Bogotá.

García, N. 1999. La globalización imaginada. México- Buenos Aires - Barcelona: Paidós.

Giménez, C. 2003. Pluralismo, multiculturalismo e interculturalidad: propuesta de clarificación y apuntes educativos. Documento Word, disponible en:

www.cesdonbosco.com/revista/impresa/8/estudios/texto_c_gimenez.doc Consultado el 1 de abril de 2014. 
Gómez, E. 2006. Migración: contexto, ciudadania y vecindad. Disponible en: http:// www.uclm.es/bits/sumario/48.asp. Consultado el 19 de abril de 2014.

Houtart, F. 2011. El camino a la utopía y el bien común de la humanidad, La Paz: Ruth Casa.

Kymlicka, W. 2009. Las odiseas multiculturales: Las nuevas politicas internacionales de la diversidad. Barcelona: Paidós.

Kymlicka, W. 1996. Ciudadanía multicultural: una teoría liberal de los derechos de las minorías. Barcelona: Paidós.

Kymlicka, W. \& Norman, W. 1997. El retorno del ciudadano. Una revisión de la producción reciente en teoría de la ciudadanía. Revista Ágora, Nº.7: 5-42.

Layton-Henry, Z. 1990. Political Rights of Migrant Workers in Western Europa, London: Sage.

Martiniello, M. 2001. La nouvelle Europe migratoire. Bruxelles : Labor.

Mesa, M. 2006. Globalización, ciudadanía y derechos: la ciudad multicultural, Papeles, $\mathrm{N}^{\circ} 95: 11-21$.

Mignolo, W. 2002. Geopolítica del conocimiento y diferencia colonial, Traducción del articulo: Geopolitics of knowledge and colonial difference, The South Atlantic Quarterly, Vol. 101, N²: 57-96.

Munévar, D. \& Wabgou, M. 2008. Transnationalism and Dominican Women: Intersections between Gender, Migration and Development. Asian Women, Vol. 24 (2): 43-74.

Palacios, G. 1995. Glocalización: nueva edad media, gobierno mundial y fin del Estado. En: Victor Manuel Moncayo (ed.). Constitución política y reorganización del Estado. Pp.27-53. Bogotá: Universidad Nacional de Colombia y UPTC.

Peñas, F.2005. ¿Es posible una teoría de Relaciones Internacionales? Revista Académica de Relaciones Internacionales, $\mathrm{N}^{\circ} 1$ : 1-32, disponible en http://www. relacionesinternacionales.info/ojs/article/view/3.html Consultado el 18 de abril de 2014.

Quijano, A. 2012. "Bien vivir»: entre el «desarrollo»y la des/colonialidad del poder. Viento Sur, Nº. 122: 36-56.

Quijano, A. 2000a. Colonialidad del poder, eurocentrismo y América Latina, en Edgardo Lander (comp.) La colonialidad del saber: eurocentrismo y ciencias sociales. Perspectivas Latinoamericanas Pp. 201-246. Buenos Aires: CLACSO. 
Quijano, A. 200ob. Colonialidad del poder y clasificación social. Journal of WorldSystems Research, Vol. XI, № 2: 342-386.

Rodríguez, D. 2007. Prólogo, en Políticas y modelos de acogida. Una mirada transatlántica: Canadá, Alemania, Francia y los Países Bajos. Documentos CIDOB, Serie: Migraciones, №. 12: 7-42. Barcelona: CIDOB.

Roth, A. \& Wabgou, M. (eds.). 2009. Las políticas públicas de las diversidades. Identidades y emancipación. Bogotá: Universidad Nacional de Colombia.

Sermeño, Á. 2000. Ciudadanía, derechos multiculturales y democracia liberal. Revista Realidad, № 75: 293-304.

Silveira, H. 2000. La vida en común las sociedades multiculturales. Aportaciones para un debate. En: Identidades comunitarias y democracia. Pp. 11-46. Madrid: Trotta.

Smith, M. 2003. Transnationalism, the State, and the Extraterritorial Citizen. En: Politics \& Society, Vol. 31 (4): 467-502.

Soriano, R. 2006. Voces de mujeres desde la inmigración: Una comparativa entre el asentamiento de marroquies en España y mexicanas en EE.UU. Working Paper 133, Center for Comparative Immigration Studies, San Diego: University of California.

Sow, P. 2007. Diásporas africanas y mundialización: de la representación histórica a la toma de conciencia. En: Ferran Iniesta (ed.), Africa en diáspora: Movimientos de población y políticas estatales. Pp. 135-150. Barcelona: Fundación CIDOB, Serie Migraciones.

Temper, L., Yánez, I., Sharife, K., Ojo, G. \& Martínez-Alier, J. (coords.). 2013. Towards a Post-Oil Civilization: Yasunization and Otherinitiatives to Leave Fossil Fuels in the Soil, Environmental Justice Organizations, Liabilities and Trade (EJOLT) Report No. 6.

Velázquez, F. 2003. La participación ciudadana en Bogotá: Mirando el presente, pensando el futuro, Alcaldía Mayor de Bogotá, Instituto Distrital de Cultura y Turismo, Departamento Administrativo de Acción Comunal, Bogotá.

Vertovec, S. 2001. Políticas multiculturales y formas de ciudadanía en las ciudades europeas. Papeles de Población. Vol. 7 (28): 221-241.

Wabgou, M. 2013a. Multiculturalismo en un juego de contextos estatales, regionales y globales en África. Análisis. Revista Colombiana de Humanidades. № 82: 87-109.

Wabgou, M. 2013b. Cooperación internacional desde abajo: acercamientos entre pueblos africanos, suramericanos y asiáticos. En: Erli Marín Aranguren \& María Romero Amaya (eds.) Cuando el Sur piensa el Sur: los giros de la cooperación al desarrollo. Pp.37-60. Bogotá: Universidad Externado de Colombia. 
Wabgou, M. 2013c. Educación Superior: un espacio de inclusión y visibilización para los afrodescendientes en Colombia. Ponencia, XIII Seminario construcción cultural afroamericana y su inserción social: conmemoración día nacional de la afrocolombianidad, organizado por la Corporación Ancestros, Universidad del Cauca, Ministerio de Cultura, E. Santa Elena, Popayán, Martes 21 de mayo.

Wabgou, M. 2012. ¿Es posible pensar las migraciones internacionales desde el enfoque universal de ciudadanía?: el Estado y la ciudadanía ante el desafio de la inmigración. Revista Ciencia Politica, № 14: 113-139.

Wabgou, M. 2010. Diásporas africanas en Colombia ¿Puntos de encuentro para el diálogo intercultural y político? Revista Pensamiento Jurídico. № 27: 295-310.

Wabgou, M. 2008. Kenia: Ante los desafios del multipartidismo y la democracia liberal. Nova Africa, № 23: 25-38

Wallerstein, I. 1997. La Reestructuración Capitalista y el Sistema-mundo. Disponible en: http://www.binghamton.edu/fbc/archive/iwlameri.htm Consultado el 23 de abril de 2014 .

Walsh, C. 2012. El pluralismo jurídico: el desafio de la interculturalidad. Nova-merica. No $133: 32-37$.

Walsh, C. 2010. Interculturalidad crítica y educación intercultural. En: Jorge Viaña; Catherine Walsh \& Luis Tapia, Construyendo interculturali $\neg$ dad crítica. Pp. 75-96. La Paz: Convenio Andrés Bello.

Walsh, C. 2009. Interculturalidad, Estado, Sociedad. Luchas (de)coloniales de nues $\neg$ tra época. Quito: Abya Yala//Universidad Andina Simón Bolívar.

Walsh, C. 2006. Interculturalidad y (de)colonialidad: diferencia y nación de otro modo. En: Desarrollo e interculturalidad, imaginario y diferencia: la nación en el mundo Andino. Pp 27-43. Quito: Academica de la Latinidad.

Walsh, C. 2005. (Re)pensamiento critico y (de)colonialidad. En: Catherine Walsh (ed.). Pensamiento crítico y matriz (de)colonial. Reflexiones latinoamericanas. Pp. 13-35. Quito: Abya-Yala/ Universidad Andina Simón Bolívar.

Walsh, C. 2002. La (re)articulación de subjetividades politicas y diferencia colonial en Ecuador: Reflexiones sobre el capitalismo y las geopolíticas del conocimiento. En: Catherine Walsh; Freya Schiwy \& Santiago Castro-Gómez (eds.). Indisciplinar las ciencias sociales: Geopoliticas del conocimiento y colonialidad del poder. Perspectivas desde lo andino. Quito: Abya Yala//Universidad Andina Simón Bolívar.

Wenden, C. 2004. El fenómeno migratorio en Europa. En: Madeleine Andebeng Labeu Alingué (coord.) Migraciones internacionales: Un mundo en movimiento. Bondades y Retos de las migraciones. Pp. 79-125. Bogotá: Universidad Externado de Colombia. 


\section{Maguemati Wabgou}

Pensar las ciudadanías multiculturales: una apuesta para revisitar la ciudadanía intercultural en las sociedades actuales. Artículo de reflexión.

Wiesenfeld, E. 2006. El rescate de las comunidades en el marco de la Globalización. Athenea Digital. N 9: 46-57

Zapata, R. 2003. La Ciudadanía en Contextos de Multiculturalidad: Procesos de cambios de paradigmas. Anales de la Cátedra Francisco Suárez. Nº 37: 173-199. 